\title{
Biologia futura: embryo-maternal communication via progesterone-induced blocking factor (PIBF) positive embryo-derived extracellular vesicles. Their role in maternal immunomodulation
}

\author{
Julia Szekeres-Bartho ${ }^{1,2,3,4} \cdot$ Timea Csabai $^{1,2,3,4} \cdot$ Eva Gorgey ${ }^{1,2,3,4}$
}

Received: 9 November 2020 / Accepted: 17 December 2020 / Published online: 29 January 2021

(c) The Author(s) 2021

\begin{abstract}
Paternal antigens expressed by the foetus are recognized as foreign. Therefore,- - according to the rules of transplantation immunity - the foetus ought to be "rejected". However, during normal gestation, maternal immune functions are re-adjusted, in order to create a favourable environment for the developing foetus. Some of the mechanisms that contribute to the altered immunological environment, for example, the cytokine balance and NK cell function, with special emphasis on the role of progesterone and the progesterone-induced blocking factor (PIBF) will be reviewed.
\end{abstract}

Keywords Progesterone $\cdot \mathrm{PIBF} \cdot \mathrm{MHC} \cdot \mathrm{NK}$ cell

\section{Novelty and innovation}

In 1953, the transplantation immunologist Sir Peter Medawar, asked the question: how does the pregnant mother contrive to nourish within itself, for many weeks or months, a fetus that is an antigenically foreign body?".

During the past more than 50 years, it has become evident that the immunological relationship of the mother and the foetus does not follow the rules of transplantation immunology. Pregnancy is characterized by profound alterations of the endocrine functions. Progesterone concentrations increase throughout pregnancy and in addition to its role in preparing the endometrium for implantation, this hormone plays a very important part in creating a tolerant

Julia Szekeres-Bartho

Szekeres.julia@pte.hu

1 Department of Medical Biology, Central Electron Microscope Laboratory, Medical School, Pecs University, 12 Szigeti Street, 7624 Pecs, Hungary

2 National Laboratory On Reproduction, János Szentágothai Research Centre, Pecs University, Pecs, Hungary

3 Endocrine Studies, Centre of Excellence, Pecs University, Pecs, Hungary

4 MTA - PTE Human Reproduction Research Group, Pecs, Hungary immunological milieu. Recent data suggest that extracellular vesicles are - at least in part-responsible for messaging between the two sides of the foeto-maternal unit.

\section{Background}

The primary role of the immune system is to protect the organism from dangerous foreign antigens. Pregnancy presents a unique task; while controlling emerging infections, the immune system is also required to create a favourable environment for the foetus. Though the presence of antipaternal and anti-foetal antibodies in the sera of multiparous women clearly shows that though pregnancy is recognized by the immune system, the semi-allogeneic foetus is tolerated throughout gestation (Billington 1992).Progesterone and its downstream mediator; the progesterone-induced blocking factor (PIBF) are important players in re-adjusting the function of the maternal immune system during pregnancy.

This paper reviews the mechanisms contributing to maternal immune adaptation to pregnancy, focussing on the roles of progesterone and PIBF. 


\section{How does the immune system recognize pregnancy?}

The embryonic trophoblast, which forms the interface between mother and foetus, shows a tightly regulated and limited expression pattern of MHC antigens. While-except for a small amount of HLA-C-, polymorphic MHC antigens are absent (Billington and Bell 1983), two non-polymorphic HLA antigens such as HLA-G and HLA-E are expressed by the extravillous trophoblast.

In the absence of polymorphic HLA, trophoblast-presented antigens are unlikely to be recognized by $\mathrm{T}$ cells in an MHC-restricted fashion.

HLA-E on the other hand serves as ligand for the CD94/ NKG2A inhibitory receptor, which is present on most decidual NK cell populations, and HLA-E binding to the receptor downregulates the killing activity of the NK cell.

\section{FETAL SIDE}

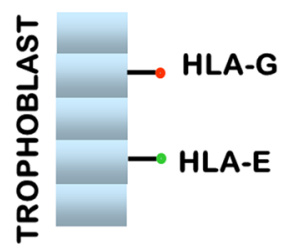

\section{ANTIGEN PRESENTATION}

Fig. 1 Recognition of trophoblast-presented foetal antigens presented by maternal immune cells. Because of its unique HLA-expression pattern the trophoblast is resistant to both T cell- and NK cell-mediated lysis. In the absence of polymorphic HLA antigens T cells will not recognize trophoblast-presented antigens, while HLA-E binding to the inhibitory receptors will inactivate NK cells. Gamma/delta T cells do - on the other hand-recognize foreign antigens without MHC restriction
The decidua contains high numbers of activated $\gamma \delta$ T cell receptor-positive cells (Liu et al. 1997). $\gamma \delta \mathrm{T}$ cells are able to recognize unprocessed foreign antigens without MHC restriction; therefore, these cells might be candidates for detecting trophoblast-presented antigens (Heyborne et al. 1994). This is supported by the fact that the majority of decidual $\gamma \delta \mathrm{T}$ cells are activated and suggests that indeed this population might be responsible for recognizing foreign antigens presented by the trophoblast (Fig. 1).

Activated lymphocytes express nuclear progesterone receptors which have been demonstrated in peripheral blood $\gamma \delta \mathrm{T}$ cells (Szekeres-Bartho et al. 2001) and in peripheral blood NK cells (Arruvito et al. 2008) of pregnant women. The link between progesterone and the immune system is partly established by lymphocyte progesterone receptors. Following the recognition of foetal antigens, $\gamma \delta \mathrm{T}$ cells become activated and express progesterone receptors (Szekeres-Bartho et al. 2001). Progesterone binding to its receptor results in gene activation and the synthesis of mediator proteins, for example, PIBF (Szekeres-Bartho et al. 1985).

\section{PIBF}

The PIBF1 gene is located on chromosome 13 in humans and chromosome 14 in mice. It is transcribed to 16 different mRNAs, the longest of which contains 18 exons and codes for the full-length $90 \mathrm{kDa}$ PIBF protein (Polgar et al. 2003). The full-length PIBF is a component of the pericentriolar satellite (Kim et al. 2012) and plays a role in cell cycle regulation and the control of invasion. Smaller isoforms resulting from alternative splicing are localized in the cytoplasm (Lachmann et al. 2004) are secreted and act in a receptormediated fashion. Upon ligand binding, the GPI-anchored PIBF receptor forms a heterodimer with the alpha chain of the IL-4 receptor and activates the Jak/STAT signalling pathway resulting in a Th2-type cytokine production by the target cell (Kozma et al. 2006) (Fig. 2).
Fig. 2 The PIBF receptor is a GPI-anchored molecule, which — upon ligand bindingforms a temporary association with the alpha chain of the IL-4 receptor, and this complex activates the Jak/STAT pathway

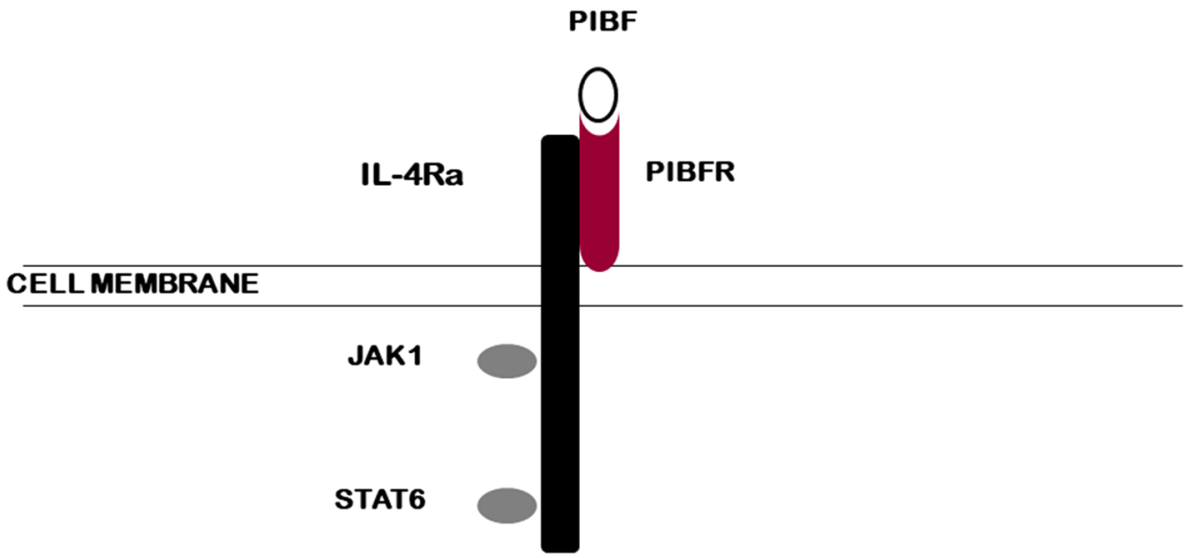


PIBF is required for the establishment and maintenance of pregnancy, both in humans and mice. PIBF induces decidual transformation of endometrial stromal cells, which is a prerequisite for successful implantation (Mulac-Jeričević et al. 2019). In the mouse, endometrium PIBF expression peaks during the implantation window (Mulac-Jeričević et al. 2019), suggesting its role in implantation.

In the sera of pregnant women, PIBF concentrations continuously increase throughout gestation and fall before labour (Polgár et al. 2004). In spontaneous miscarriage or preterm delivery serum, PIBF concentrations are significantly lower than the normal gestational age-matched levels (Polgár et al. 2004).

PIBF mediates the immunomodulatory effects of progesterone. These include altered cytokine production and NK cell function.

\section{Cytokine production during pregnancy}

The suitable immunological environment for the developing foetus is established via the dialogue of maternal and foetal cytokines (Wegmann et al. 1993). A recent longitudinal study, in pregnant women showed that, though the immune system is activated and exerts antigen-specific cytotoxic $\mathrm{T}$ cell responses, IL-10 production and the frequency of regulatory $\mathrm{T}$ cells are increased (Shah et al. 2018).

Though implantation requires mild local inflammatory conditions, pregnancy is characterized by a Th2-dominant cytokine pattern (Wegmann et al. 1993), and consequently by increased immunoglobulin synthesis (Gaunt and Ramin 2001) and decreased cell-mediated responses (Tangri et al. 1994). This is reflected by the modified clinical manifestations of autoimmune and infectious diseases during pregnancy. Approximately $70 \%$ of women with rheumatoid arthritis (a predominantly cell-mediated autoimmune disorder) experience a temporary remission during gestation (Adams and Nelson 2008).

Intracellular pathogens, for example, viruses are the most common vertically transmitted pathogens through the decidual-placental interface (Stockman et al. 2004). Infections caused by intracellular pathogens, flair up during pregnancy, while the defence mechanisms to extracellular bacteria infections stay intact.

In humans, there is a well-established relationship between peripheral cytokine patterns and the outcome of pregnancy ( $\mathrm{Ng}$ et al. 2002). The levels of LIF, IL-4, IL-10 and M-CSF produced by decidual $\mathrm{T}$ cells of women suffering from unexplained spontaneous abortion are lower than those in normal pregnant women, indicating that these cytokines may contribute to the maintenance of pregnancy (Piccinni 2005).
Activated peripheral lymphocytes of healthy pregnant women produce significantly higher levels of Th2-associated cytokines and less Th1-associated cytokines than those of women with recurrent miscarriages (Raghupathy et al. 2000).

\section{NK activity during pregnancy}

Decidual NK cells which constitute $60-70$ per cent of the lymphocytes in the first trimester human or mouse decidua differ from circulating NK cells both in their phenotype and function. While the majority of human peripheral NK cells express the low density of CD56 (CD56 $\left.{ }^{\mathrm{dim}}\right)$ and high levels of the FCgRIII (CD16), decidual NK cells express a high density of the CD56 molecule (CD56 $6^{\text {bright }}$ ) and no CD16.

Decidual NK cells are fully equipped for cytotoxicity and can fight intrauterine infections if needed (Quillay et al. 2016). These cells degranulate in response to hCMVinfected autologous decidual cells (Siewiera et al. 2013), or during a spontaneous abortion in mice (Lima et al. 2014), but despite the abundant presence of cytotoxic molecules in their cytoplasmic granules, during normal pregnancy, decidual NK activity is low (Rukavina et al. 1995). Their low cytotoxic potential is only partly explained by the presence of HLA-E on the trophoblast, which acts as a ligand for the NKG2A inhibitory receptor.

Decidual NK cell cytotoxicity might damage the trophoblast and lead to pregnancy termination. In humans, recurrent miscarriages are associated with an increased number of endometrial NK cells (Quenby et al. 2009), together with a reduced $\%$ of $\mathrm{CD} 16^{-} \mathrm{CD} 56^{\text {bright }}$ cells among the former (Yamada et al. 2003). Pregnant women with spontaneous abortions of unknown aetiology have a high NK activity (Putowski et al. 2004).

\section{The role of progesterone-dependent immunomodulation in the establishment and maintenance of pregnancy}

Studies with progesterone receptor knockout mice revealed, that during pregnancy, immunologically active PIBF is produced via activation of the classical Progesterone Receptor A (Mulac-Jeričević et al. 2019). PIBF induces increased production of Th2 cytokines (Szekeres-Bartho and Wegmann 1996), and the high endometrial expression of PIBF corresponding to the implantation window suggests that this molecule might be involved in implantation.

Studies on PIBF-deficient pregnant mice not only confirm the importance of PIBF in the establishment and the maintenance of pregnancy, but also reveal new details about the action of this molecule on the immune system. Pregnant mice rendered PIBF-deficient in the peri-implantaton period had significantly less implantation sites compared 
to the controls, and the embryos that were implanted nevertheless were resorbed in later pregnancy. The number of PIBF + decidual NK cells decreased, while both decidual and peripheral NK activity increased in PIBF-deficient mice (Csabai et al. 2020). Earlier data show that the increased resorption rates in pregnant mice induced by anti-PIBF antibody were corrected by treating the mice with anti-NK-1.1 antibody (Szekeres-Bartho et al. 1996), suggesting that PIBF protects pregnancy partly, by keeping NK activity at a low level. Laškarin et al. (1999) reported that PIBF blocks upregulation of perforin expression in decidual lymphocytes, while anti-PIBF antibodies reversed the progesterone mediated reduction in the cytolytic activity of decidual lymphocytes. Faust et al. (1999) showed that PIBF inhibits cytotoxicity of peripheral NK cells by inhibiting degranulation, but without interfering with target conjugation. Based on these data, it cannot be ruled out that PIBF present in the cyoplasmic granules contributes to low decidual NK activity of decidual NK cells..

A recent study showed that IL-33 induced expression of PIBF1 by decidual B cells prevents preterm labour both in humans and mice (Huang et al. 2017). While a distinct layer of PIBF $+\mathrm{B}$ cells was present in the chorio-decidual interface of control mice, B cells were completely depleted from the deciduas of anti-PIBF treated mice (Csabai et al. 2020).

The genes implicated in $\mathrm{T}$ cell activation were significantly downregulated in peripheral CD4 + and increased in CD8 + of PIBF-deficient animals (Csabai et al. 2020). The gene for IL-4 was significantly downregulated in peripheral CD4+ cells while that of IL-12A was upregulated in CD8 + cells, of PIBF-deficient mice, suggesting that in the absence of PIBF, T cells differentiate to Th1, rather than Th2 (Csabai et al. 2020).

Taken together, these data suggest that a significant part of the immunological pregnancy-protective effect of progesterone is manifested via its downstream mediator PIBF. Following recognition of foetally derived antigens, maternal lymphocytes become activated and develop progesterone receptors. Progesterone binding to the receptor induces PIBF synthesis, which, by controlling NK activity and by inducing a Th2-biased immune response, allows pregnancy to go to term.

\section{The peri-implantation embryo communicates with the maternal immune system via extracellular vesicles}

Signals emitted by the developing embryo might reach and re-adjust the function of the maternal immune system. Embryo culture media exert an immunosuppressive activity (Daya and Clark 1986). In line with this, incubation of human peripheral lymphocytes with the culture media of fertilized eggs, but not that with follicular fluid resulted in increased IL-10 mRNA expression by the lymphocytes (Kelemen et al. 1998).

These data suggest that embryo-derived messages can influence the maternal immune response; however, little is known about the mechanism of signalling. EVs might be considered as a means for conveying the information from the embryo to the mother.

Extracellular vesicles (EVs) are membrane-coated structures that may express phosphatidylserine (PS) in their membrane.

All types of cells produce EVs, which transport various cargos, for example, cytokines that could activate signalling pathways, and thus alter the biological functions of the target cells (Desrochers et al. 2016).

The message carried by EVs affects the reproductive process at different points.

Some of the miRNAs in follicular fluid target genes that regulate oocyte growth as well as several other reproduction pathways, and endocrine functions (Sang et al. 2013). Qu et al. (2017) showed that the negative effects of culture media replacement during embryo culture are due to the loss of embryo-derived EVs and can be corrected by exosome supplementation. EV-mediated interactions between the endometrium and the blastocyst promote implantation (Ng et al. 2013). EVs from a human uterine epithelial cell express the extracellular matrix metalloprotease inducer (Braundmeier et al. 2012,) which induces the expression of MMPs, thus EVs might also play a role in endometrial remodelling (Barundmeier et al. 2012). These data suggest that embryo-derived EVs do indeed carry molecules that contribute to normal embryo development.

The peri-implantation embryo produces EVs both in vitro, and in in vivo (Pallinger et al. 2017), which are taken up by close by cells (Saadeldin et al. 2014).

Embryo-derived EVs might communicate with the maternal immune system by presenting antigens (Montecalvo et al. 2008), carrying MHC molecules (Nolte-'t Hoen et al. 2009) or cytokines (Pizzirani et al. 2007).

Pallinger et al. (2018) reported that PIBF-containing embryo-derived EVs affect the cytokine production of peripheral lymphocytes. Incubation of murine spleen cells with embryo-derived EVs increased the number of IL- 10 + cells among peripheral CD 8 + cells, but not in the CD4+ population, and pre-treatment of EVs with an anti-PIBF antibody abrogated this effect. Their data suggest that PIBF transported by the EVs from the embryo to maternal lymphocytes might induce increased IL-10 production by the latter, this way contributing to the Th2dominant immune responses described during pregnancy.

This pathway might have its significance in reproduction. Because embryo-derived EVs might transport various 


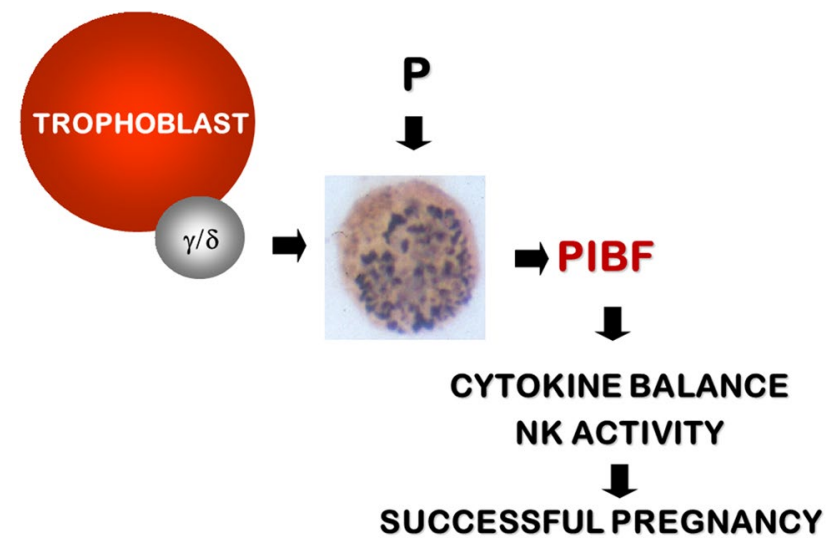

Fig. 3 Progesterone-dependent immunomodulation in pregnancy been implemented. In the future, the research ought to move in this direction.

Acknowledgements This work was supported by GINOP-2.3.2-15201600021., PTE ÁOK-KA 2017-22, EFOP-3.6.1.-16-2016-00004, EFOP-3.6.3-VEKOP-16-2017-00009 and OTKA K125212

Funding Open Access funding provided by University of Pécs.

Open Access This article is licensed under a Creative Commons Attribution 4.0 International License, which permits use, sharing, adaptation, distribution and reproduction in any medium or format, as long as you give appropriate credit to the original author(s) and the source, provide a link to the Creative Commons licence, and indicate if changes were made. The images or other third party material in this article are included in the article's Creative Commons licence, unless indicated otherwise in a credit line to the material. If material is not included in the article's Creative Commons licence and your intended use is not permitted by statutory regulation or exceeds the permitted use, you will need to obtain permission directly from the copyright holder. To view a copy of this licence, visit http://creativecommons.org/licenses/by/4.0/.

\section{References}

molecules,-PIBF, among others-, it cannot be ruled out that these structures act as means of foeto-maternal or materno-foetal communication in the peri-implantation period.

\section{Major current outstanding issues/questions}

During the past decades, our understanding of the foeto-maternal relationship has become broader. By now, it became obvious that the success of gestation depends on an intense interaction between the conceptus and the mother. Several mechanisms that take part of the result from this communication have been identified, and some of these have been reviewed in this paper.

- Foetal antigens presented by the trophoblast are recognized by decidual $\gamma / \delta \mathrm{T}$ cells, which upon recognition, become activated and express nuclear progesterone receptors

- Progesterone binding to the receptors results in gene activation and mediator proteins are produced.

- PIBF, a downstream mediator of progesterone affects implantation and contributes to the Th2-dominant cytokine balance and reduced NK activity, both required for successful gestation (Fig. 3).

- The embryo and the foetus communicate with the maternal side via extracellular vesicles.

This knowledge, however, has not been so far successfully converted to clinical treatment of pregnancy disorders. Most recurrent miscarriages clearly have an immunological background, yet no successful immune diagnosis or therapy has
Adams Waldorf KM, Nelson JL (2008) Autoimmune disease during pregnancy and the microchimerism legacy of pregnancy. Immunol Invest 37:631-644

Arruvito L, Giulianelli S, Flores AC, Paladino N, Barboza M, Lanari C, Fainboim L (2008) NK cells expressing a progesterone receptor are susceptible to progesterone-induced apoptosis. J Immunol 180:5746-5753

Billington WD, Bell SC. (1983) Fetal histocompatibility antigens and maternal immune responses. Ciba Found Symp. 96:69-88. Review.

Billington WD (1992) Transfer of antigens and antibodies between mother and foetus. In: Coulam CB, Faulk WP, McIntyre J (eds) Immunological obstetrics. W.W. Norton \& Co., New York, pp 290-304

Braundmeier AG, Dayger CA, Mehrotra P, Belton RJ Jr, Nowak RA (2012) EMMPRIN is secreted by human uterine epithelial cells in microvesicles and stimulates metalloproteinase production by human uterine fibroblast cells. Reprod Sci 19:1292-1301

Csabai T, Pallinger E, Kovacs AF, Miko E, Bognar Z, SzekeresBartho J (2020) Altered immune response and implantation failure in progesterone-induced blocking factor-deficient mice. Front Immunol 11:349

Daya S, Clark DA (1986) Immunosuppressive factor (or factors) produced by human embryos in vitro. N Engl J Med 24:1551-1552

Desrochers LM, Bordeleau F, Reinhart-King CA, Cerione RA, Antonyak MA (2016) Microvesicles provide a mechanism for intercellular communication by embryonic stem cells during embryo implantation. Nat Commun 7:11958

Faust Zs, Laškarin G, Rukavina D, Szekeres-Bartho J (1999) Progesterone induced blocking factor inhibits degranulation of NK cells. Am J Reprod Immunol 42:71-75

Gaunt G, Ramin K (2001) Immunological tolerance of the human fetus. Am J Perinatol 18:299-312

Heyborne K, Yang-Xin Fu, Nelson A, Farr A, O’Brien R, Born W (1994) Recognition of trophoblasts by gamma/delta T cells. J Immunol 153:2918-2926

Huang B, Faucette AN, Pawlitz MD, Pei B, Goyert JW, Zhou JZ et al (2017) Interleukin-33-induced expression of PIBF1 by decidual B cells protects against preterm labor. Nat Med 23:128-135 
Kelemen K, Paldi A, Tinneberg H, Torok A, Szekeres-Bartho J (1998) Early recognition of pregnancy by the maternal immune system. Am J Reprod Immunol 39:351-355

Kim K, Lee K, Rhee K (2012) CEP90 is required for the assembly and centrosomal accumulation of centriolar satellites, which is essential for primary cilia formation. PLoS ONE 7(10):e48196

Kozma N, Halasz M, Polgar B, Poehlmann TG, Markert UR, Palkovics T, Keszei M, Par G, Kiss K, Szeberenyi J, Grama L, Szekeres-Bartho J (2006) Progesterone-induced blocking factor activates STAT6 via binding to a novel IL-4 receptor. J Immunol 176:819-826

Lachmann M, Gelbmann D, Kálmán E, Polgár B, Buschle M, Von Gabain A, Szekeres-Barthó J, Nagy E (2004) PIBF (progesterone induced blocking factor) is overexpressed in highly proliferating cells and associated with the centrosome. Int $\mathrm{J}$ Cancer 112:51-60

Laškarin G, Faust Z, ŠTrbo N, Sotošek V, Szekeres-Bartho J, Podack ER, Rukavina D (1999) Progesterone directly and indirectly affects perforin expression in cytolytic cells. Amer J Reprod Immunol 42(5):312-320

Lima PD, Tu MM, Rahim MM, Peng AR, Croy BA, Makrigiannis AP (2014) Ly49 receptors activate angiogenic mouse $\mathrm{DBA}^{+}$uterine natural killer cells. Cell Mol Immunol 11:467-764

Liu WJ, Gottshall SL, Hansen PJ (1997) Increased expression of cell surface marker on endometrial $\mathrm{g} / \mathrm{d} \mathrm{T}$ cell receptor intraepithelial lymphocytes induced by the local presence of the sheep conceptus. Am J Reprod Immunol 37:199-205

Montecalvo A, Shufesky WJ, Stolz DB, Sullivan MG, Wang Z, Divito SJ et al (2008) Exosomes as a short-range mechanism to spread alloantigen between dendritic cells during $\mathrm{T}$ cell allorecognition. J Immunol 180:3081-3090

Mulac-Jeričević B, Šućurović S, Gulic T, Szekeres-Bartho J (2019) The involvement of the progesterone receptor in PIBF and Gal-1 expression in the mouse endometrium. Am J Reprod Immunol 81(5):e13104

Ng SC, Gilman-Sachs A, Thaker P, Beaman KD, Beer AE, Kwak-Kim $\mathrm{J}$ (2002) Expression of intracellular Th1 and Th2 cytokines in women with recurrent spontaneous abortion, implantation failures after IVF/ET or normal pregnancy. Am J Reprod Immunol 48:77-86

$\mathrm{Ng}$ YH, Rome S, Jalabert A, Forterre A, Singh H, Hincks CL et al (2013) Endometria 1 exosomes/microvesicles in the uterine microenvironment: a new paradigm for embryo-endometrial crosstalk at implantation. PLoS ONE 8:e58502

Nolte-'t Hoen EN, Buschow SI, Anderton SM, Stoorvogel W, Wauben MH (2009) Activated T cells recruit exosomes secreted by dendritic cells via LFA-1. Blood 113:1977-1981

Piccinni MP (2005) T cells in pregnancy. Chem Immunol Allergy 89:3-9

Pizzirani C, Ferrari D, Chiozzi P, Adinolfi E, Sandonà D, Savaglio E et al (2007) Stimulation of P2 receptors causes release of IL-1beta-loaded microvesicles from human dendritic cells. Blood 109:3856-3864

Polgar B, Kispal G, Lachmann M, Paar C, Nagy E, Csere P, Miko E, Szereday L, Varga P, Szekeres-Bartho J (2003) Molecular cloning and immunologic characterization of a novel cDNA coding for progesterone-induced blocking factor. J Immunol 171(11):5956-5963

Polgár B, Nagy E, Mikó E, Varga P, Szekeres-Barthó J (2004) Urinary progesterone-induced blocking factor concentration is related to pregnancy outcome. Biol Reprod 71:1699-1705

Putowski L, Darmochwal-Kolarz D, Rolinski J, Oleszczuk J, Jakowicki J (2004) The immunological profile of infertile women after repeated IVF failure (preliminary study). Eur J Obstet Gynecol Reprod Biol 112:192-196

Pallinger E, Bognar Z, Bodis J, Csabai T, Farkas N, Godony K et al (2017) A simple and rapid flow cytometry-based assay to identify a competent embryo prior to embryo transfer. Sci Rep 6:39927

Quillay H, El Costa H, Duriez M, Marlin R, Cannou C, Madec Y, de Truchis C, Rahmati M, Barré-Sinoussi F, Nugeyre MT, Menu E (2016) NK cells control HIV-1 infection of macrophages through soluble factors and cellular contacts in the human decidua. Retrovirology 13:39

Quenby S, Nik H, Innes B, Lash G, Turner M, Drury J, Bulmer J (2009) Uterine natural killer cells and angiogenesis in recurrent reproductive failure. Hum Reprod 24:45-54

Qu P, Qing S, Liu R, Qin H, Wang W, Qiao F et al (2017) Effects of embryo-derived exosomes on the development of bovine cloned embryos. PLoS ONE 12:e0174535

Raghupathy R, Makhseed M, Azizieh F, Omu A, Gupta M, Farhat R (2000) Cytokine production by maternal lymphocytes during normal human pregnancy and in unexplained recurrent spontaneous abortion. Hum Reprod 15:713-718

Rukavina D, Rubesa G, Gudelj L, Haller H, Podack ER (1995) Characteristics of perforin expressing lymphocytes within the first trimester of human pregnancy. Am J Reprod Immunol 33:394-404

Saadeldin IM, Kim SJ, Choi YB, Lee BC (2014) Improvement of cloned embryos development by co-culturing with parthenotes: a possible role of exosomes/microvesicles for embryos paracrine communication, Cell. Reprogr. 16: 223e234.

Sang Q, Yao Z, Wang H, Feng R, Zhao X, Xing Q et al (2013) Identification of microRNAs in human follicular fluid: characterization of microRNAs that govern steroidogenesis in vitro and are associated with polycystic ovary syndrome in vivo. J Clin Endocrinol Metab 98:3068-3079

Shah NM, Imami N, Johnson MR (2018) Progesterone modulation of pregnancy-related immune responses. Front Immunol 9:1293

Siewiera J, El Costa H, Tabiasco J, Berreb A, Cartron G, LeBouteiller P, Jabrane-Ferrat N (2013) Human cytomegalovirus infection elicits new decidual natural killer cell effector function. PLoSPathog 9:e1003257

Stockman LJ, Lowther SA, Coy K, Saw J, Parashar UD (2004) SARS during pregnancy, United States. Emerg Infect Dis 10:1689-1690

Szekeres-Bartho J, Kilar F, Falkay G, Csernus V, Török A, Pacsa AS (1985) The mechanism of the inhibitory effect of progesterone on lymphocyte cytotoxicity: I. Progesterone-treated lymphocytes release a substance inhibiting cytotoxicity and prostaglandin synthesis. Am J Reprod Immunol Microbiol 9:15-18

Szekeres-Bartho J, Wegmann TG (1996) A progesterne-dependent immunomodulatory protein alters the Th1/Th2 balance. J Reprod Immunol 31:81-95

Szekeres-Bartho J, Faust Z, Varga P, Szereday L, Kelemen K (1996) The immunological pregnancy protective effect of progesterone is manifested via controlling cytokine production. Am J Reprod Immunol 35:348-351

Szekeres-Bartho J, Barakonyi A, Miko E, Polgar B, Palkovics T (2001) The role of $\mathrm{g} / \mathrm{d} \mathrm{T}$ cells in the feto-maternal relationship. Semin Immunol 13:229-233

Wegmann TG, Lin H, Guilbert L, Mosmann TR (1993) Bidirectional cytokine interactions in the maternal-fetal relationship: is successful pregnancy a TH2 phenomenon? Immunol Today 14:353-356

Yamada H, Morikawa M, Kato EH, Shimada S, Kobashi G, Minakami H (2003) Pre-conceptional natural killer cell activity and percentage as predictors of biochemical pregnancy and spontaneous abortion with normal chromosome karyotype. Am J Reprod Immunol 50:351-354 